\title{
El patrimonio arqueológico posthispánico del sur bonaerense a través de las colecciones
}

Vanesa N. Bagaloni"

\section{Resumen}

En este artículo se presenta un estado general de la cuestión sobre el patrimonio arqueológico posthispánico de una microrregión del sur bonaerense. Se abordan las colecciones arqueológicas posthispánicas tanto públicas (museos de San Cayetano, Tres Arroyos y Lobería) como privadas (colecciones López Alfaro y Magret). Se plantea un estudio basado en dos aspectos: 1) identificar los materiales arqueológicos posthispánicos registrados en el área y 2) evaluar el estado de las muestras estudiadas y analizar las condiciones de gestión y resguardo del patrimonio arqueológico. Además, se discute la importancia de las colecciones en la investigación arqueológica posthispánica del sur bonaerense. Este abordaje destaca el indudable aporte de la "materialidad arqueológica" así como los relatos asociados a las mismas, siendo en algunos casos un relato sesgado y descontextualizado y, en otros, más plural de las voces del pasado. No obstante el intento de una visión antropológica desde la conformación inicial de los museos públicos abordados, los períodos colonial, independentista y republicano se encontraron desdibujados arqueológica e históricamente, invisibilizándose parte del pasado y de los discursos no oficiales asociados no sólo del papel activo de las comunidades indígenas locales y regionales durante estos períodos sino también de los primeros pobladores fronterizos no indígenas.

\section{The post-Hispanic archaeological heritage from southern Buenos Aires province through its collections}

\begin{abstract}
In this article, we address the state of the art in post-Hispanic archaeological heritage from a southern micro-region of the Buenos Aires province. Here, we study both public (the San Cayetano, Tres Arroyos and Lobería museums) and private (the López Alfaro and Magret collections) post-Hispanic archaeological collections. Our analysis is centered on two main themes: 1) to identify the post-Hispanic archaeological record registered in the area, and 2) to evaluate the preservation of the studied samples,

Recibido:

18 de noviembre de 2017

Aceptado:

9 de agosto de 2018

\section{Palabras clave}

Colecciones públicas y privadas Patrimonio arqueológico Sur bonaerense Período posthispánico

\section{Keywords}

Public and private collections Archaeological heritage Southern Buenos Aires province Post-Hispanic period 
analyzing the conditions of management and protection of this archaeological heritage. In addition, we discuss the importance of these collections in post-Hispanic archaeological research in the south of Buenos Aires Province. Our approach highlights the important contribution of "archaeological materiality" in the narratives created around these collections. At times, these narratives are biased and decontextualized, while at other times they serve to democratize a variety of voices from the past. Nevertheless, even though there was an attempt to achieve an anthropological vision in the public museums we studied, we found that the colonial, independence and republican periods suffered from historical and archaeologically blurring, whereby parts of the past and the discourse and active agency of both local and regional indigenous communities during those periods, as well as that of the first non-indigenous frontier settlers was rendered invisible.

\section{Introducción}

Este trabajo surge a partir de un interés particular en las colecciones arqueológicas posthispánicas de una microrregión del sur bonaerense y tiene como fin identificar el conjunto de bienes culturales del área, evaluar su estado, ubicación y distribución en el marco tanto de las esferas públicas como privadas. La microrregión de estudio incluye los partidos de San Cayetano, Tres Arroyos, Gonzales Chaves y sur de Benito Juárez (Figura 1). La localidad de Lobería fue abordada debido a que uno de los museos allí ubicados cuenta con materiales procedentes de distintos sitios arqueológicos del partido de San Cayetano.

Asimismo, el período posthispánico en la región pampeana se inicia con la llegada de los españoles al Río de la Plata a comienzos del siglo XVI. Según criterios contemporáneos de la historia (F. Barcos, comunicación personal, 2018) este período se podría dividir en: 1) período colonial (1535-1780), 2) período tardo-colonial (1780-1810), 3) período independentista o de guerras revolucionarias (1810-1820), 4) período postrevolucionario o de guerras civiles (1820-1852), 5) período de formación del estado nacional (1852-1880), 6) período de consolidación del estado-nación (1880-1930) y otros períodos históricos que implican contextos y procesos que exceden al rango cronológico de nuestro estudio y que llegan hasta la actualidad.

Este estudio se enmarca en una investigación mayor sobre la arqueología de los asentamientos fronterizos y rurales de la Frontera Sur y Costa Sur (siglo XIX) (Bagaloni, 2014), cuyo objetivo inicial fuera reconocer, registrar y analizar los objetos arqueológicos recolectados por profesionales, propietarios y/o aficionados, evaluando la procedencia (lugar puntual y contexto), el estado de conservación y sus características tecnomorfológicas para estimar su origen, función y cronología. Por ello, las conclusiones vertidas en este artículo constituyen un ensayo sobre el patrimonio arqueológico a partir de 10 años de trabajo y experiencia en la microrregión. A su vez, para el análisis y entendimiento de ese patrimonio nos basamos en herramientas conceptuales que surgen desde el quehacer de dicha investigación científica. El conocimiento y comunicación de las colecciones arqueológicas posthispánicas públicas y privadas por parte del ámbito académico y fuera de este (en algunas entidades y/o instituciones locales) constituye uno de los puntapiés iniciales para el proceso de valoración y construcción patrimonial de dichos conjuntos por la comunidad local y regional.

En este artículo se presenta un análisis sobre la cuestión del patrimonio arqueológico del área basado en dos aspectos: 1) la identificación de los materiales arqueológicos 


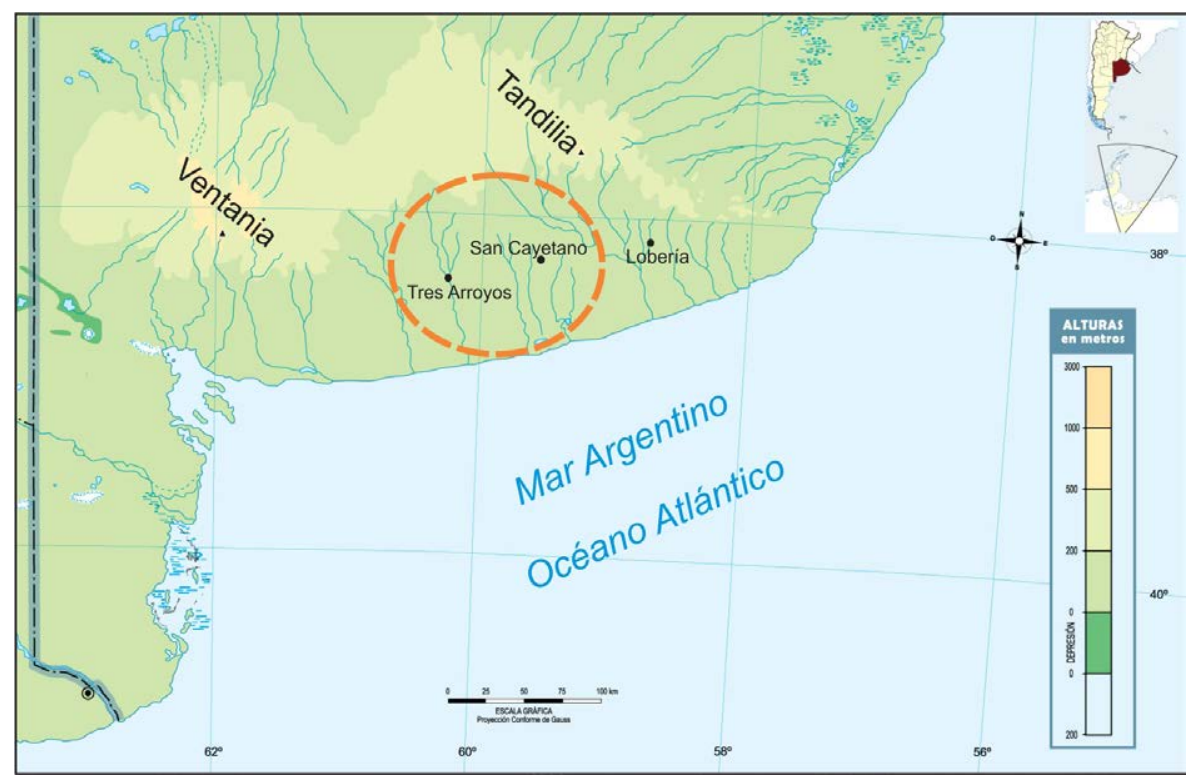

Figura 1. Ubicación de la microrregión de estudio y las ciudades donde se hallan las colecciones abordadas.

posthispánicos hallados en tres museos públicos - Museo Regional "Faustino I. Queipo" de San Cayetano (MSC), Museo Municipal "José A. Mulazzi” de Tres Arroyos (MTA), Museo de Historia y Ciencias Naturales "Gesué P. Noseda" de Lobería (ML) y en las colecciones privadas de los Sres. Alberto López Alfaro (CLA) y Oscar Magret (CM) ubicadas en sus propiedades particulares, este punto incluye una breve historia del surgimiento, desarrollo y características de cada museo/colección (Tabla 1) y 2) la evaluación del estado de las muestras estudiadas y análisis las condiciones de gestión de ese patrimonio arqueológico (a nivel municipal, provincial y nacional) con especial énfasis en su manejo y resguardo. Finalmente, se realiza una discusión central sobre la importancia de las colecciones en la investigación arqueológica posthispánica del sur bonaerense.

\section{Marco teórico y metodológico}

El registro arqueológico se transforma en patrimonio cultural (dentro de éste, el arqueológico) por medio de una valoración social, es decir, por la importancia o el significado que le otorgue la comunidad local a los restos materiales dados a conocer por el ámbito científico y no científico. Sólo a través de este proceso de patrimonialización o de activación patrimonial es que el registro arqueológico toma tal carácter. Y para que este proceso de construcción social se inicie se necesita de la comunicación pública de los materiales arqueológicos de interés científico (Mariano y Conforti, 2013). A su vez, el patrimonio cultural cambia y se transforma según los valores de cada sociedad en los distintos momentos históricos que transita (Lowenthal, 1985 en Endere, 2004, p. 451).

El patrimonio arqueológico dentro de una comunidad es definido por diversos procesos y mecanismos de memoria/olvido y de identidades individuales y colectivas a través de, por ejemplo, los museos, siendo los que representan, distorsionan y/o restringen el pasado (Colasurdo, Sartori y Escudero, 2010) así como constituyen espacios de construcción de identidades, de producción de discursos y significados, de reproducción social y de consumo cultural (Chaparro, 2012). Las comunidades locales -integradas por funcionarios, gestores del área de cultura, arqueólogos, 


\begin{tabular}{|c|c|c|c|}
\hline Museo / Datos & MSC & MTA & ML \\
\hline Partido & San Cayetano & Tres Arroyos & Lobería \\
\hline $\begin{array}{l}\text { Creación / Traslado o } \\
\text { Refacción }\end{array}$ & $90 \% / 2007$ & 1979 & $1960 / 1993$ \\
\hline Estructura edilicia interna & $\begin{array}{l}\text { Hall de entrada con historia } \\
\text { de Faustino I. Queipo. } \\
4 \text { salas (paleontológica, } \\
\text { arqueológica, histórica y } \\
\text { ferrocarril). Depósito. Andén } \\
\text { de muestras transitorias. }\end{array}$ & $\begin{array}{l}\text { Múltiples salas. En planta baja } \\
\text { (Arqueología): arqueología, Arroyo } \\
\text { Seco } 2 \text { y arqueología argentina. } \\
\text { En planta alta (Historia de Tres } \\
\text { Arroyos): contacto indígena- } \\
\text { criollo, etapa fundacional, } \\
\text { 19oo-1930, desde 193o hasta el } \\
\text { presente. Oficinas. Depósito. } \\
\text { Biblioteca. Archivo Histórico. Patio } \\
\text { arqueológico. Auditorio. }\end{array}$ & $\begin{array}{l}4 \text { salas (paleontológica, } \\
\text { arqueológica, taxidermia } \\
\text { e historia local). Gabinete- } \\
\text { Laboratorio. Depósito. Oficina. }\end{array}$ \\
\hline Exposiciones & Permanente y transitorias & Permanente y transitorias & Permanente \\
\hline Escala & Regional & Municipal & Regional \\
\hline
\end{tabular}

Tabla 1. Información comparada de los tres museos públicos donde se encuentran las colecciones estudiadas.

visitantes de los museos y colecciones privadas, descendientes de grupos originarios, docentes y alumnos, periodistas, aficionados y demás ciudadanos-generan múltiples significados del pasado a través del patrimonio arqueológico así como dejan entrever conflictos y/o miradas contrapuestas producto de ese mismo proceso de conocimiento, reconocimiento y resignificación de sus propias experiencias.

Siguiendo el trabajo realizado por Salerno (2014, pp. 15-34), la intervención del arqueólogo en una comunidad genera una serie de relaciones institucionales y personales. Distintos procesos de construcción y resignificación del pasado surgen durante y después de la investigación arqueológica dada a partir del estudio de la materialidad. Asimismo, hay infinitas instancias anteriores y paralelas donde las mismas comunidades locales establecen sus propias valoraciones y maneras de apropiación de la cultura material pasada antes de la intervención de los arqueólogos. Estos últimos son los que producen una ruptura y una resignificación de esos criterios de valor y acción de los objetos materiales (de conocimiento, de comunicación y de conservación), del saber y de las narrativas que generan tanto las comunidades como los arqueólogos en el presente. Es así como se origina una discusión entre los saberes cotidianos y el conocimiento científico, entre los especialistas (los arqueólogos) y los no especialistas (diversos agentes de la comunidad local que no son arqueólogos). Dentro de estos no especialistas encontramos a los coleccionistas locales que mediante su actividad permiten visualizar la circulación de materiales arqueológicos en el ámbito privado, los cuales han colaborado históricamente en la conformación de museos oficiales y/o dañado contextos arqueológicos mediante la búsqueda de las piezas, en ocasiones fomentado el mercado ilegal y el tráfico de piezas (Guráieb y Frère, 2008). Asimismo, nos ayudan a comprender las representaciones locales y el uso que hacen del pasado, que muchas veces entran en conflicto con las científicas. También dentro de este segmento se reconocieron distintas minorías sociales, como por ejemplo las comunidades indígenas locales y los descendientes de personalidades locales importantes (por ejemplo, familiares actuales de Teófilo Gomila), siendo interlocutores esenciales y participantes de la interpretación de su propio pasado.

Como resultado de todo este complejo proceso de construcción social y simbólica, se reconocen nuevos espacios de interacción, conflicto, entendimiento y legitimación del pasado local y regional en el presente. Es así que entendemos a los museos como espacios de educación no formal y de comunicación donde se estimula la memoria, la identificación y la resignificación del pasado (Chaparro, 2012; Colasurdo et al., 2010; Conforti, 2012). A través de los objetos, su ubicación, de los carteles y/o afiches que los 
acompañan - y que a veces los describen, explican y contextualizan-, de la relación entre ellos, etc. se genera una multiplicidad de significados donde cada visitante se apropia del patrimonio arqueológico e histórico experimentando una reelaboración cultural del mismo (Dujovne, 1995). Esta conceptualización de lo que es y de lo que implica un museo se desdibuja cuando nos acercamos al mundo de los aficionados y de los coleccionistas y de sus espacios cotidianos de exposición, significación, contención y conservación de las piezas. La idea de "museo informal" se repite en determinados espacios, habitaciones y escritorios de las estancias de campo y de las casas de los pueblos y ciudades estudiadas donde se destinan una o varias vitrinas a la exposición de objetos significativos para una familia por generaciones.

El pasado es sostenido y definido, entre otras cosas, a través de los objetos arqueológicos que constituyen un bien material invaluable y no renovable sobre el cual se sientan las bases tangibles que legitiman, resignifican y/o contradicen el relato oral y escrito sobre el mismo. Este relato, a su vez, se nutre en este intercambio de objetos concretos y diversos actores (investigadores, museólogos, educadores, coleccionistas, estancieros, políticos, escolares y demás ciudadanos) generando múltiples pasados e historias en el presente. A su vez, según Pomian una colección tiene la función de "conectar el mundo de quien la observa con los mundos evocados por los objetos", es decir, conectar el mundo de lo visible con lo invisible (Pomian, 1978 en Podgorny, 2005, p. 238).

Actualmente, el concepto de patrimonio cultural en Arqueología abarca desde momentos paleoindios hasta tiempos recientes y tiene un sentido cotidiano, popular, múltiple - nacional, indígena, gaucho, rural, urbano, industrial-, dinámico y multívoco. Se considera al público como destinatario y partícipe y a la comunidad de origen de ese patrimonio, teniendo en cuenta que dicho patrimonio puede ser objeto de reclamos, llegando a revalorizar la memoria comunitaria y la dimensión emocional del pasado. Además, la noción de patrimonio es una construcción social y cultural presente e implica una intención de lo que se quiere resguardar (Endere, 2009, p. 27). Precisamente, el siglo XIX estuvo teñido de una visión eurocentrista del mundo y de la cultura. Durante esta época, la idea de patrimonio cultural estuvo fuertemente ligada a la construcción de la identidad nacional. Los estados latinoamericanos nacientes necesitaban contar una propia historia y educar al ciudadano generándole un sentido de identidad fundamentalmente asociada a una tradición hispano-católica, a la homogenización cultural producto del mestizaje biológico y a la exaltación de los héroes nacionales en detrimento, a partir de la negación, del largo pasado indígena (Endere, 2009).

Siendo la arqueología una práctica política que incide directamente en su contexto mayor (Curtoni y Endere, 2003; Funari, 2004; entre muchos otros) es sumamente relevante la gestión de los recursos no renovables como el patrimonio arqueológico mediante el conocimiento, la planificación, el control y la difusión del mismo (Ballart Hernández y Tresseras, 2001; Querol, 2010). En este sentido, diversos autores coinciden en que se requiere de la promulgación de una legislación provincial adecuada y precisa, de la adopción de una visión integral y holística del patrimonio, de estrategias colectivas y planes de manejo de los recursos apropiadas, de la inversión tanto pública como privada, de la inclusión de nuevos grupos de interés y del público para la gestión del patrimonio arqueológico para contemplar la diversidad cultural y reducir el conflicto social, entre muchos otros aspectos (Endere y Pedrotta, 2010; Endere, Mariano, Conforti y Mariano, 2015; Guráieb y Frère, 2008).

Por último, las colecciones se registraron y fotografiaron en los museos y casas de particulares. El análisis e interpretación de los restos arqueológicos se basó en una serie de variables según el tipo de material que ya han sido desarrolladas en múltiples oportunidades (Bagaloni, 2014). 
1. Entre los proyectos de investigación que se vienen desarrollando en el sur bonaerense sobre grupos indígenas prehispánicos se encuentran los correspondientes a los equipos de G. Politis, M. Gutiérrez, M. Bonomo, A. Massigoge, R. March, C. Bayón y N. Flegenheimer, sólo para mencionar algunos.

\section{El caso de estudio}

A partir del estudio de la cultura material proveniente de las colecciones arqueológicas y de las fuentes escritas y gráficas que se presentan a continuación y sus contextos históricos asociados, es que comienza a concebirse un relato escrito y oral, una reconstrucción del pasado en el sur bonaerense a través de su puesta en valor en diferentes tiempos por la interacción entre distintos actores.

Los museos MSC, MTA y ML han aportado información material y escrita relacionada con las casas de negocios, pulperías, estancias y fortines de la microrregión estudiada y sobre algunas de las problemáticas abordadas (Tabla 2). Las colecciones CLA y $\mathrm{CM}$ también contribuyeron con elementos materiales diagnósticos. La primera colección privada está conformada por objetos que constituyen una herencia familiar y otras piezas aisladas recolectadas en los campos aledaños a la estancia San Ignacio, propiedad de la familia López Alfaro. La segunda es producto de una excavación de rescate y constituye la colección con mayor número de piezas relevadas en el área y referida a la casa de negocio Chapar. Cabe destacar que las colecciones de los museos se conformaron a partir del comercio, el intercambio, la donación y la herencia de pobladores y aficionados, así como las prospecciones y excavaciones de distintos sitios arqueológicos cercanos a los mismos y enmarcados dentro de variados proyectos de investigación científica ${ }^{1}$. Estos equipos científicos cedieron parte de las piezas recuperadas en diversos sitios para su exhibición permanente en los museos abordados.

\section{Museo Regional "Faustino I. Queipo"}

El MSC surgió a partir de la inquietud de un grupo de aficionados a la arqueología y a la paleontología conducidos por el Sr. Faustino Idelfonso Queipo (1921-1983) que reunió una importante colección de piezas y documentación del partido de San Cayetano. Luego de la muerte de Queipo en la década de 1990, se creó una comisión de historia local que eventualmente concretó el sueño de formar un museo regional. En octubre del año 2007 se reinauguró el nuevo museo en una vieja estación de ferrocarril con el apoyo de la Municipalidad de San Cayetano y la colaboración de la arqueóloga Agustina Massigoge. El museo cuenta con cuatro salas (paleontología, arqueología, historia e historia de la estación del ferrocarril) con materiales recuperados en terreno por aficionados donados por propietarios de distintos campos del partido y por el municipio. Además, presenta una sala de exposiciones transitorias. Hoy día, luego de varios años de abierto al público y con gran actividad, este museo - que depende de la Dirección de Cultura de dicha municipalidad- se encuentra parcialmente cerrado funcionando solamente dos veces por semana y con un horario muy reducido, sin personal especializado. En mayo de 2013, fue víctima del vandalismo cuando desconocidos iniciaron un foco de incendio intencional que provocó la pérdida de piezas irrecuperables (“Incendio en el Museo Faustino Queipo", 2013).

El relevamiento y registro de las piezas procedentes del MSC se realizó en el año 2006. Anteriormente el Dr. M. Bonomo y la Dra. A. Massigoge habían efectuado el estudio de los materiales líticos. Ambos investigadores describen la presencia de bolas de boleadoras de distintas características realizadas sobre variados tipos de rocas, puntas de flechas, elementos de molienda tales como manos y morteros y otros instrumentos líticos (Bonomo, 2005; Massigoge, 2009). No se descarta que algunos de estos materiales podrían corresponder a momentos posteriores a la conquista europea ya que se encuentran descontextualizados y, a su vez, es común encontrar artefactos como raspadores, raederas y bolas de boleadoras en contextos fronterizos como por ejemplo, tolderías y fortines de la frontera Sur y Costa Sur (Bagaloni, 2014; Crivelli, Eugenio, Pardiñas y Silveira, 1997; Eugenio, Aldazábal y Silveira, 2007; Pedrotta, 2005). Además, existen referencias etnohistóricas en la región (p. ej. Guinnard, [ca.1860] 1941) del uso de instrumentos 


\begin{tabular}{|l|c|c|c|c|c|}
\hline Material / Colección & MSC & MTA & ML & CLA & CM \\
\hline Vítreo & 0 & 1 & 33 & 0 & 664 \\
Cerámico & 2 & 0 & 3 & 3 & 8 \\
Metal & 10 & 5 & 0 & 33 & 3 \\
Óseo & $* 2$ & 0 & 22 & 0 & 4 \\
Lítico & $* 1$ & 2 & 7 & $*_{2}$ & 0 \\
Otros & 5 & 18 & 0 & 11 & 0 \\
\hline Total & 17 & 26 & 65 & 47 & 679 \\
\hline
\end{tabular}

Tabla 2. Materiales posthispánicos analizados de colecciones púbicas y privadas. Dentro de "Otros" se consignaron fotografías, documentos, mapas y muebles de madera correspondientes a asentamientos fronterizos ylo rurales de la zona de estudio.

Notas: "1 Materiales estudiados por Bonomo (2005) y *2 por Massigoge (comunicación personal, 2007, 2009), no especifican cantidad.

líticos tanto por grupos originarios como por población criolla evidenciando indicios de la interacción social y las relaciones interétnicas desplegadas en los espacios fronterizos en el marco de procesos de mestizaje e interacción cultural. Entre los objetos posthispánicos de clara procedencia europea y/o criolla analizados $(n=17)$ se encontraron distintos elementos, sobre todo cerámicos y de metal, además de fuentes escritas.

Dentro de los materiales cerámicos se identificó una botella de gres de ginebra y/o agua mineral entera procedente de la pulpería Cristiano Muerto, ubicada a orillas del arroyo homónimo. Asimismo, se describió una teja francesa (Figura 2A) con inscripción "Pierre Sacoman - St. Henry * Marseille" hallada en la casa de negocio Chapar construida en 1845 (partido de Gonzales Chaves). Entre los metales consignados se destacó un sable completo de oficial con su funda del Ejército Argentino del año 1885 y varias pistolas y revólveres con una cronología que abarca desde mediados de siglo XIX hasta inicios del siglo XX. Entre las fuentes documentales se registró un mapa denominado "Cartas de las Pampas del Sud" elaborado por Adolfo Alsina (1872), dos imágenes tomadas en el año 1860 de la pulpería Cristiano Muerto y el diario de cuentas de la pulpería La Gaviota del año 1913. Por último, este museo resguarda un palenque de madera de la entrada a esta última pulpería.

\section{Museo Municipal "José A. Mulazzi”}

El MTA, fundado en 1979 y dependiente de la Municipalidad de Tres Arroyos, cuenta con una gran colección de materiales prehispánicos de sitios locales y de la región pampeana que han sido estudiados por distintos equipos de investigación mencionados anteriormente. En la planta baja se encuentra una exposición permanente que introduce a la labor arqueológica y aborda diversas temáticas de la arqueología pampeana y del territorio argentino y se exponen materiales del sitio Arroyo Seco 2 y de la colección Mulazzi (Conforti, 2012; Conforti, Endere y Martín, 2007; Endere, 2004). En la planta alta también se halla una sala permanente relacionada con la historia del siglo XIX de Tres Arroyos que recorre desde los primeros asentamientos fronterizos, la etapa fundacional y diferentes aspectos (entre ellos economía, política, cultura, educación, deportes, moda y vida cotidiana) desde 1900 hasta el presente. Además, hay un depósito de materiales procedentes de distintas prospecciones arqueológicas efectuadas en la región, un archivo histórico y una biblioteca.

A diferencia de los trabajos anteriores sobre el MTA, aquí profundizamos sobre los materiales arqueológicos posthispánicos de la zona de estudio y la documentación 
contextual sobre ese período registrada en el museo. El MTA tiene una sección dedicada a los primeros exploradores y los iniciales asentamientos criollos de la región. Esto se constató en el año 2009 cuando se relevaron en dicha sección piezas recuperadas en el fortín Machado (partido de Tres Arroyos, ver Figura 2B) y donadas por la familia D' Angelo. Entre ellos, se consignaron partes de armas constituidas por posibles vainas de sables y porciones de revólveres como, por ejemplo, una culata de revólver con sistema Lefaucheux de origen europeo y de mediados de siglo XIX. De este mismo fortín proceden un pico de una botella cuadrada de ginebra y dos bolas de boleadora de granito, una de ellas con un surco perimetral. Aunque no se sabe la ubicación exacta del hallazgo de estas boleadoras, es decir si proceden de la zona de instalación propiamente dicha del fortín o de las inmediaciones del campo o de una antigua laguna aledaña al sitio que actualmente está seca, no podemos descartar la presencia de grupos indígenas anteriores o contemporáneos a la instalación militar a partir de estos objetos líticos, según lo expuesto por Gómez Romero para fortines coetáneos (Gómez Romero, 2007). En esta sección del museo se encuentra un banner con una explicación histórica básica del fortín describiendo su cronología, dimensiones y otras características. Además, la exposición cuenta con una fotografía de 1933, una fotografía actual y una maqueta donde se reconstruyen las instalaciones y dependencias que supuestamente presentaba un fortín de la época.

De igual manera, se registraron fotografías de estancias de la zona como, por ejemplo, La Libertad (1865), San Eduardo (1875) y Santa Graciana (1882). También existe una reconstrucción de un mostrador de una pulpería con distintos objetos vítreos y cerámicos, donde se mencionan algunas pulperías de la zona tales como La Española, El Médano, El Cometa, Esquina, El Boliche, Sol de Mayo, entre otras. Finalmente, este museo cuenta con un archivo digital del Juzgado Civil y Juzgado de Paz (Departamento de Historia Judicial) del partido de Tres Arroyos. En el mismo se consultaron los expedientes $(\mathrm{n}=13)$ relacionados con los Sres. Justo de la Lastra y Teófilo Gomila entre las décadas de 1880 y 1890. Esta indagación tuvo como objetivo visualizar las relaciones sociales y los conflictos personalizados por estos dos actores que habitaron tempranamente el partido de Tres Arroyos y que constituyeron pilares de los modos de vida en la frontera y en el ámbito rural y que habitaron la estancia La Libertad, sitio arqueológico estudiado por nuestro equipo (Bagaloni, 2014).

\section{Museo de Ciencias Naturales "Gesué P. Noseda”}

Producto de la iniciativa del lugareño Gesué Pedro Noseda y de Horacio Cerimelo, el ML abrió sus puertas en el año 1960 como "Museo de Historia y Ciencias Naturales del Club de Pesca de Lobería" en las instalaciones de dicho club, autogestionado por un "Grupo de Amigos" del museo. En 1993 se refunda en el mismo espacio como "Museo de Ciencias Naturales Gesué Pedro Noseda”, creándose las salas de paleontología, taxidermia de fauna autóctona y exótica, arqueología (con el acompañamiento de profesionales universitarios) e historia del partido. Aquí nos detendremos en las piezas que se encuentran en exposición y proceden del sitio posthispánico estancia La Nilda en el Paraje Dos Naciones, excavado y estudiado por Casamiquela (Casamiquela, 1969; Casamiquela y Noseda, 1970). Se trata de los restos líticos (un gran rodado de cuarcita) y óseos ( $\mathrm{n}=23$; huesos humanos de un individuo femenino con "rasgos faciales pámpidos" y restos de coipo) que integran un contexto funerario con un tipo de entierro que recuerda a los practicados por los tehuelches, cazadores nómades ecuestres de la Patagonia (Casamiquela, 1969; Casamiquela y Noseda, 1970). La cronología de este sitio se la colocó entre la segunda mitad del siglo XVIII y la primera del XIX. Por motivos de refacción del depósito en el año 2010, sólo se pudo acceder a los materiales en exposición (Figura 2C), no hallándose entre éstos los restos de caballo mencionados en dichas publicaciones. 


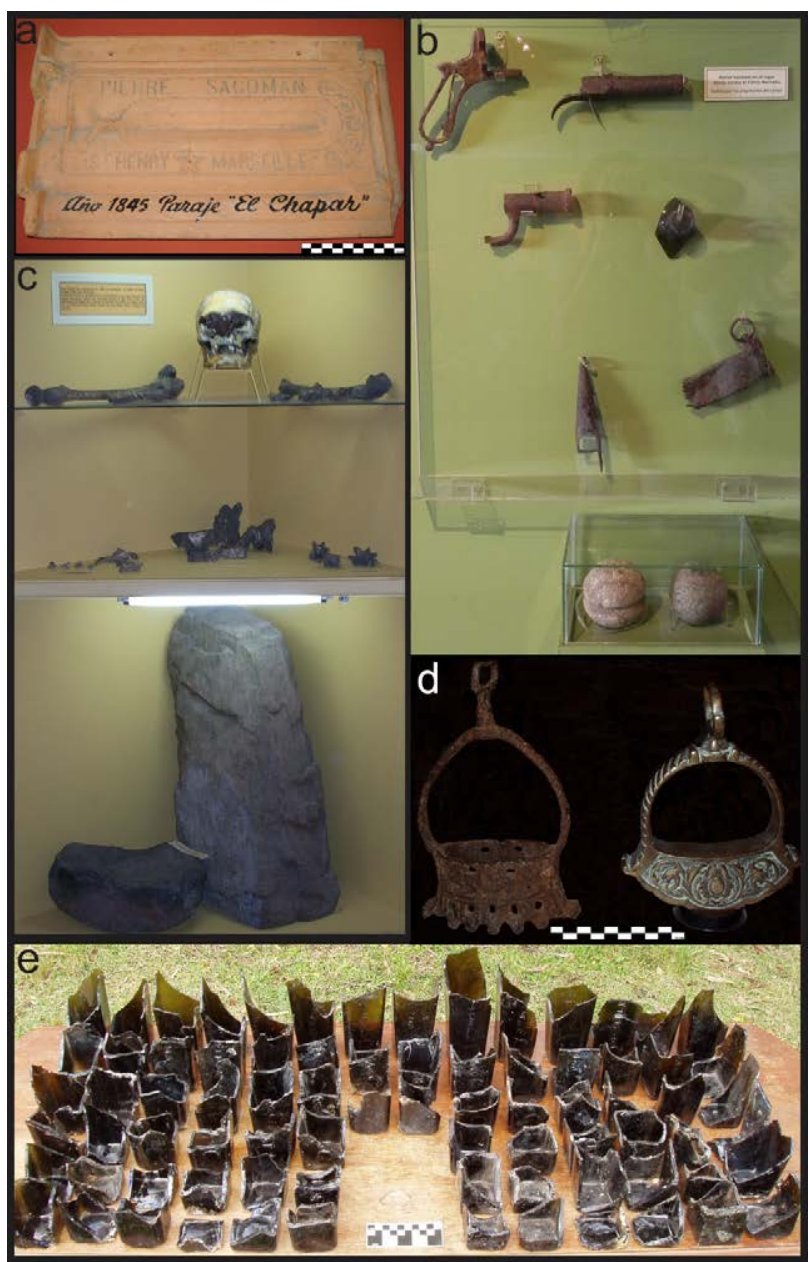

Figura 2. Materiales arqueológicos estudiados. A) teja francesa, sitio Chapar, MSC; B) objetos de metal, lítico y vidrio del Fortín Machado, $M T A ; C)$ elementos óseos y lápida, sepulcro La Nilda, ML; D) estribos, $C L A ; E)$ bases de limetas, CM.

De igual manera, en otro depósito del museo se consignaron materiales vítreos $(\mathrm{n}=33)$, cerámicos $(n=3)$ y líticos $(n=6)$ procedentes del Paso Otero y recolectados entre 1980 y 1982. Este paso, ubicado sobre el arroyo Quequén Grande, límite entre los partidos de Necochea y San Cayetano, perteneció al partido de la Lobería. Cercano a este se ubicaron la estancia y dos puestos de Nicanor Olivera (entre 1835 y 1864) y posteriormente hacia 1875 solamente quedaba un puesto rural situado próximo al paso (ver evolución de la tierra en Bagaloni, 2014). Los materiales vítreos incluyen fragmentos de botellas cuadradas o limetas $(\mathrm{n}=29)$, botellas cilíndricas, un tintero y un frasco/tarro. Algunas limetas de ginebra corresponden a la marca V. Hoytema de origen holandés y con una cronología de la segunda mitad de siglo XIX. Los restos cerámicos se hallan representados por fragmentos de lozas inglesa tipo pearlware y una porción de pared de una botella de gres de ginebra y/o agua mineral. Por último, se clasificaron seis artefactos de cuarcita, entre ellos, puntas, raederas y preformas.

\section{Colección López Alfaro}

Los antepasados de la familia López Alfaro habitaron el partido de San Cayetano desde mediados de siglo XIX. En una entrevista realizada al Sr. Alberto López Alfaro en la estancia San Ignacio en Mayo de 2007 se registraron datos y objetos relevantes desde 
la perspectiva arqueológica e histórica. A pesar de que este conjunto de materiales no ha sido estudiado en profundidad ya que solamente se tuvo contacto con los mismos en una oportunidad, es relevante mencionarlo ya que estos objetos ocupan un lugar importante en el imaginario histórico y social de los pobladores del partido. En este sentido y a modo de ejemplo, debe comentarse que esta colección ha sido expuesta en la Municipalidad de San Cayetano en la muestra histórica denominada "El Centenario en el Bicentenario", que fuera inaugurada el 17 de Marzo de 2011 (Massa, 2011). En la entrevista que mantuvimos con el Sr. López Alfaro, él relata que en un sector de la estancia denominado Loma del Indio, "tres indios" se quedaron viviendo luego de la Batalla Sol de Mayo de 1857. La zona constituye un lugar estratégico ya que desde ella se visualizan parte de los partidos de Gonzales Chaves, San Cayetano y Tres Arroyos.

Entre los objetos relevados y fotografiados expeditivamente, se encuentran bolas de boleadora $(n=25)$ de distintas características y gran variedad de tamaños y materia primas que fueron halladas en la Loma del Indio y que han sido estudiadas por la Dra. A. Massigoge (comunicación personal, 2007). Asimismo, la colección Alfaro incluye dos estribos braseros (Figura 2D) y tres bolas de cañón de metal. Uno de los estribos data aproximadamente de 1830-1835 según el entrevistado. El otro estribo corresponde al Ejército Argentino y fue guardado por su tatarabuelo, Pascual Echagüe, quien participó en la Batalla de Caseros (1852). También se relevaron piezas de loza $(\mathrm{n}=3)$ y metal $(\mathrm{n}=3)$ correspondientes a vajilla de mesa española y portuguesa, tanto de la etapa de Independencia como de la época Colonial, cencerros $(n=25)$ elaborados en diferentes tipos de metales y formas y muebles de madera $(n=11)$. Estos dos últimos, cencerros y muebles, presentan un rango cronológico que va desde mediados del siglo XIX y hasta las primeras décadas del siglo XX según descripción de los propietarios.

\section{Colección Magret}

Esta colección está constituida por restos arqueológicos provenientes de la casa de negocio "Chapar" localizada en el partido de Gonzales Chaves, a unos $700 \mathrm{~m}$ de la margen derecha del arroyo Pescado Castigado. Según su propietaria, la Sra. María Estela Libertad de Delaie, entrevistada en el año 2006, este establecimiento funcionó desde el 17 de Marzo de 1845. En el año 2010, al fallecer dicha propietaria, se cerraron sus puertas. No obstante, por más de 115 años mantuvo su estructura edilicia original: techos de madera de forma cóncava con aislante de tierra, tejas francesas de Marsella y paredes de ladrillos con adobe.

Hacia diciembre del año 1997, debido a la construcción de una balanza para pesar camiones en esta casa de negocio, se descubrieron materiales arqueológicos en un foso y en dos pozos por fuera de ésta. La extracción de dichos materiales fue efectuada por el lugareño sancayetanense Oscar Magret y fue filmada por los medios locales. Esta colección se relevó en los años 2007 y 2011, tanto en su casa ubicada en el pueblo de San Cayetano como en la estancia San Luis perteneciente a la familia y cercana a dicha casa de negocio. La misma se encuentra conformada por 679 piezas (ver Tabla 2) provenientes del foso antes mencionado $(n=584)$, de un jagüel ubicado en la casa de negocio $(n=75)$ y por materiales que fueron recolectados superficialmente en un campo arado aledaño a esta $(n=20)$. La totalidad de las piezas enteras y fragmentos se contabilizaron, se clasificaron y se fotografiaron.

En líneas generales, el 97,8\% de los materiales vítreos $(\mathrm{n}=664)$ está representado por una gran variedad de botellas y recipientes cilíndricos como damajuanas, botellas cuadradas (Figura 2E), vasos y copas. Se analizó en profundidad una muestra de 372 fragmentos vítreos cuyo estudio detallado y de importancia metodológica se presenta en la tesis doctoral de la autora (Bagaloni, 2014). Se destaca una amplia variedad de contenidos como vino, champagne, ginebra, cerveza, agua mineral, jerez, hesperidina, 
salsa inglesa, entre otros. Estos productos embotellados se importaron de Francia, Gran Bretaña, España y posiblemente EE.UU. desde principios de siglo XIX, aunque su comercialización masiva en el Río de la Plata se dio a partir de mediados del mismo siglo (Bagaloni, 2017). El porcentaje restante está conformado por fragmentos de una tetera de porcelana inglesa de la primera mitad de siglo XIX, dos botellas de gres de cerveza inglesa, huesos de Bos taurus, una tijera de tusar de metal, una lata (posiblemente de sardinas o caballa) y una llanta de carro.

\section{La importancia de las colecciones en la investigación arqueológica}

La mayoría de los conjuntos arqueológicos recuperados por diversos coleccionistas, aficionados y propietarios presentaron procedimientos disímiles y sin sistematicidad de registro de los materiales, careciendo de datos exactos del lugar de procedencia y de asociación contextual del hallazgo. Asimismo, es dudosa la representatividad de dichas muestras, a causa de una posible recolección selectiva de los materiales arqueológicos en terreno y de aquellos guardados por distintos descendientes a lo largo del tiempo con cierta intencionalidad. Además, es factible que durante la formación de los depósitos muchos de los materiales se hayan mezclado y procedan de lugares distintos y/o pertenezcan a diferentes épocas. A esto puede agregarse, en ciertos casos, un resguardo inadecuado de las colecciones (en cajas sin rótulos, en tachos de cemento, metal o plástico, en lugares con humedad, al aire libre, etc.) que propicia la pérdida y/o alteración de los materiales como hemos constatado en algunos de nuestros casos de estudio. No obstante este panorama, es indudable el aporte arqueológico e histórico brindado tanto por las colecciones públicas como por las privadas para las generaciones venideras.

En este sentido, abordaremos dos líneas complementarias para el entendimiento de por qué es substancial incorporar el estudio de colecciones tanto públicas como privadas antes y durante el proceso de investigación de nuestra microrregión de estudio. Por un lado, por la importancia de la "materialidad arqueológica" en sí misma, aquellos objetos rescatados y/o donados que son por su naturaleza parte del patrimonio arqueológico, histórico y cultural de una localidad y/o región al que puede acceder tanto el investigador y/o el curador como el aficionado y/o coleccionista así como, en algunos casos, el público en general. Estos objetos a veces pueden ser remitidos a un tiempo histórico particular, a un contexto de origen, un uso específico y relacionarlos a determinados asentamientos fronterizos y/o rurales. Y por el otro lado, por el "discurso arqueológico posthispánico" generado tanto en el ámbito público por los museos como en el privado por anticuaristas y coleccionistas siendo, en muchos casos, los que sientan las bases de los conocimientos establecidos y compartidos por la comunidad local y regional. Y que, en distintas ocasiones a priori o a posteriori, se contraponen, se entrelazan, confluyen y se resignifican con los conocimientos científicos, creando un nuevo relato. Este último punto lo trataremos en el siguiente apartado.

En cuanto al primer aspecto relacionado con la "materialidad arqueológica", las colecciones públicas y privadas estudiadas contienen una gran diversidad de restos arqueológicos que remiten a asentamientos fronterizos y/o rurales factibles de localizar en la microrregión de estudio: puestos y estancias, fortines y casas de negocio. Estos asentamientos se ubican principalmente en la cercanía de arroyos como en el caso de la casa de negocio Chapar, el fortín Machado, el puesto Paso Otero, la pulpería Cristiano Muerto, la estancia La Libertad, entre otros; y en lagunas, como la pulpería La Gaviota. El caso del enterratorio indígena estudiado por Casamiquela (1969), cuyos restos se hallan expuestos en el Museo de Lobería, es excepcional y se trata del único de este tipo descubierto hasta el momento para la zona aledaña al área de estudio, incluyendo a la propia microrregión abordada. 
En general los conjuntos analizados se encuentran conformados en mayor proporción por materiales de procedencia europea, tales como recipientes de vidrio, elementos de metal y botellas y vasijas de cerámica (ver Tabla 2). Estas piezas exhiben variadas características tecnomorfológicas, dimensiones y funcionalidades, habiéndose podido determinar en casi todos los casos su origen y cronología. De este modo, se logró estimar que gran parte de estos objetos de la vida cotidiana de la frontera Sur y Costa Sur provenían fundamentalmente de Gran Bretaña, Francia, España, Holanda y Bélgica, entre muchos otros países europeos. Se trata de productos que ingresaron al Río de la Plata desde fines del siglo XVIII y comienzos del siglo XIX, aunque a mediados de esta última centuria se produjo un "boom" de las importaciones y por tanto el consumo de determinados artículos se hizo masivo (Bagaloni, 2014). Además, los siguen en menor cantidad restos óseos humanos, restos de fauna autóctona y doméstica y artefactos líticos (p. ej. bolas de boleadora en el sitio fortín Machado). Como citamos anteriormente este último grupo de materiales líticos es considerado hipotéticamente y su contrastación se encuentra actualmente en curso en el caso de dicho fortín mediante el estudio sistemático de distintos conjuntos líticos recuperados en el sitio.

De este modo, dadas las características particulares de los conjuntos materiales se logró estimar un rango cronológico relativo para las colecciones públicas y privadas que corresponden fundamentalmente a la segunda mitad del siglo XIX. De igual forma, en algunos casos se pudo establecer la pertenencia de grupos arqueológicos a un tipo específico de asentamiento fronterizo y/o rural. La mayoría de los artefactos analizados remiten a tareas específicas relacionadas con contextos sistémicos donde se evidencian distintas actividades de funcionamiento, prácticas de consumo y hábitos rurales decimonónicos. Por ejemplo, la gran cantidad de recipientes de vidrio (botellas, frascos, vasos y copas) y gres (botellas) descubiertos en Chapar son esperables en un comercio fronterizo y rural minorista que funcionó por varias décadas. Al igual que las armas de metal y los artefactos líticos son factibles de hallar en el contexto de un fortín como el Machado y una lápida y cuerpo humano es congruente con el de una sepultura como la de Dos Naciones.

Por otro lado, estos repositorios públicos y privados conservan distintas fuentes inéditas como son los expedientes del Juzgado de Paz y del Juzgado Civil (Departamento de Historia Judicial de Tres Arroyos) entre los años 1881-1893 en el MTA y libros de contaduría de la pulpería La Gaviota en el MSC; fotografías de época de distintas estancias y pulperías en el MTA y en MSC; el video de excavación de la casa de negocio Chapar desarrollado por Caynet (el portal de noticias de San Cayetano) y las anotaciones de la extracción de los materiales efectuadas por Magret en el caso de la CM; sólo para nombrar algunas. Muchos de estos registros escritos y visuales fueron estimados en distintas etapas de la investigación doctoral de la autora siendo valorados tanto en las instancias de descubrimiento como de interpretación y aportando elementos para comprender las microhistorias, las historias locales, los procesos y contextos fronterizos y rurales, las dinámicas de estos espacios y/o ámbitos, entre otros aspectos.

A pesar de los sesgos inherentes a las colecciones estudiadas debemos asumir su aporte metodológico. Estas colecciones contribuyeron a la investigación en sí misma desde distintos lugares, como se evidencia en la tesis doctoral de la autora (Bagaloni, 2014). Nos dieron una idea de lo que es esperable en términos de materialidad, ubicación de sitios, funcionalidad de los mismos, circulación, uso y descarte de determinados ítems en el espacio fronterizo y rural. El estudio de las colecciones nos permitió orientar las primeras prospecciones, visualizar algunos de los iniciales asentamientos fronterizos, identificar distintas piezas halladas en los sitios arqueológicos, interrelacionar los asentamientos fronterizos y rurales entre sí y aportar a los problemas de nuestra investigación tales como la conformación de las líneas de frontera Sur y Costa Sur, la expansión territorial de los asentamientos criollos comerciales, las relaciones 
intersociales en el espacio fronterizo y rural, las redes de obtención y consumo de artículos nacionales y europeos, etc. Siguiendo esta línea, es necesario destacar la importancia del análisis de los materiales vítreos hallados en la casa de negocio Chapar, no sólo como muestra comparativa a nivel regional sino también por la diversidad de artículos, entre ellos bebidas y comidas, que llegaban a lugares tan remotos de la frontera bonaerense desde mediados de siglo XIX y que eran consumidos por los pobladores (Bagaloni, 2017).

\section{La construcción del pasado en el sur bonaerense a través de las colecciones arqueológicas}

Más allá de la descripción y adscripción de los conjuntos arqueológicos anteriores a contextos específicos y en algunos casos de los documentos contextuales a éstos, surge la comparación y el debate acerca de la forma en que los museos públicos y las colecciones de aficionados aquí abordados transmiten a la comunidad local y regional una idea del pasado reciente. Es decir, qué imagen/es del pasado posthispánico se construye/n en ese intercambio de ideas visuales, orales y escritas en los banners de los museos y/o de las colecciones en las vitrinas de las viviendas de pobladores locales; qué objetos deciden exponerse, cómo y para qué, dentro de qué contexto general de una sala; cómo el objeto es acompañado y/o completado con un relato visual y escrito que clasifica, sustenta y legitima al mismo y nos va generando una idea, no sólo del tiempo y espacio pasado sino que también, a veces, lo adscribe a un grupo étnico y social con características propias; cómo esos relatos generan estereotipos que desdibujan las particularidades de los actores sociales y de los espacios fronterizos y ámbitos rurales, sólo para nombrar algunos aspectos. Seguidamente, se analizan algunas de las cuestiones anteriores en los museos públicos (ver Tabla 1) y en los ámbitos privados de exposición de los objetos: la disposición espaciotemporal general que se les otorga, los períodos históricos que se enfatizan, la visión sobre los pueblos originarios y no indígenas (europeos, africanos, criollos), entre otros temas.

\section{Los museos públicos}

Las colecciones abordadas fueron el sustento material y simbólico de la narrativa de los museos locales y coleccionistas, dado por la distribución espacial de las muestras, cómo se exponen los objetos en las vitrinas, lo que no se expone, las representaciones gráficas y/o audiovisuales que acompañan y el relato sobre el pasado que se brinda a partir de ellos. En el caso de los museos de Lobería, Tres Arroyos y San Cayetano se construyó este relato arqueológico-histórico a partir del aporte de tres actores sociales activos en la conformación, exposición y comunicación de las muestras: la ciencia por medio de distintos equipos profesionales de arqueólogos, antropólogos e historiadores; algunos sectores del gobierno local y los responsables de las instituciones locales; y grupos de aficionados y ciudadanos en general que dieron el puntapié inicial mediante un ávido interés por el pasado, la historia, la identidad y la memoria local. Es así como también estos museos, sobre todo el MTA y el ML, se conformaron como lugares de encuentro y reencuentro social a través de una amplia participación en la comunidad convocando, a través de distintas propuestas, a grupos sociales, de edad y de interés (Brichetti, 2009; Conforti, 2012; Conforti et al., 2007; Endere, 2004). De esta manera, se logró comenzar a construir un patrimonio común, participativo y ciudadano respetando la mayoría de las voces, no sólo las pasadas sino también las presentes constituyendo, desde mi punto de vista, un gran avance.

No obstante, debe señalarse que el relato arqueológico-histórico acerca del período post-hispánico, el más recientemente incorporado a las exposiciones museísticas y a veces el más dificultoso de abordar, no se encuentra aún al nivel de las muestras de los grupos humanos anteriores a la conquista y ocupación española. La distribución de las 
muestras arqueológicas en el espacio basadas en un criterio cronológico, básicamente en los tres museos estudiados, estaría condicionando la mirada del pasado. El lugar físico dado a determinadas muestras o períodos históricos otorga mayor relevancia al período prehispánico en pos de los períodos colonial, tardo-colonial, independentista, post-revolucionario y de formación y consolidación del estado-nación. La autora como antropóloga y arqueóloga considera relevante que la historia local y regional propuesta en estos museos sea la más democrática, integral y holística para todos los tiempos y para todos los grupos étnicos que habitaron la región $-\mathrm{p}$. ej. grupos originarios cuyos descendientes llegan hasta nuestros días, esclavos negros, hispanos, criollos, inmigrantes europeos de fines de siglo XIX, entre muchos otros-.

En el caso del ML en la línea temporal que se plantea durante el recorrido del museo, el período post-hispánico se encuentra desdibujado. El trayecto en un sólo nivel comienza con una imponente sala paleontológica, a la cual le siguen numerosas vitrinas con restos prehispánicos provenientes de distintos sitios arqueológicos asociados a una simple cartelería. Esta muestra culmina con algunas piezas del enterramiento hallado en el paraje Dos Naciones sin mayor contextualización (ver Figura 2C) y el resto de la pequeña colección de materiales posthispánicos se encuentra en el depósito, fuera de la exhibición. En cierta forma, así se continúa la idea de inclusión de los "materiales prehistóricos" dentro de las ciencias naturales, de lo naturalmente dado, desde los descubrimientos de restos de megafauna hasta los artefactos líticos de las poblaciones indígenas y no como parte de un proceso social e histórico de los pueblos que habitaron y habitan estas tierras. A pesar que a dos cuadras se encuentra el Museo Histórico "La Lobería Grande", este comienza exponiendo en la Sala 1, la más antigua temporalmente, mapas comparativos de "La Lobería Grande" con la Lobería actual, fotografías de pulperías y una colección de armas de 1890 y marcas de hacienda del partido, entre otros, sin un relato que informe sobre los procesos sociales y culturales que se sucedieron durante el siglo XIX siendo el siglo al que pertenecen los objetos y documentos expuestos. Esta visión de los grupos humanos pasados naturalista, cientificista y tradicional debe ser reformulada, ya que ningún grupo del pasado y del presente puede ser escindido de los procesos sociales, culturales e históricos que los constituyen y traspasan.

Distinto es el caso de los museos de Tres Arroyos y San Cayetano donde hubo una intención en continuar el pasado prehispánico mediante salas específicas con referencia a distintos períodos y procesos históricos locales y regionales. Incluso en el MTA, el pasado prehispánico se presenta con una visión antropológica a través de diversos contextos espaciotemporales - materializados a través de distintas piezas arqueológicas, maquetas y banners explicativos - pertenecientes tanto a grupos originarios de la región pampeana como del resto de la Argentina. Por otro lado, en este museo existe una desconexión espacial entre el pasado posthispánico y el prehispánico, debido a que esta última muestra se encuentra en la planta baja, en un sector aislado, al cual se accede desde lugares específicos (Conforti, 2012). En cambio, la muestra posthispánica, ubicada en la planta alta, es visible a simple vista desde el hall central del museo, comenzado con la historia local de Tres Arroyos a partir del avance criollo con la conformación de la frontera bonaerense y la instalación de los primeros fortines, estancias y pulperías llegando hasta la actualidad (Figura 3A). A pesar de esta visión antropológica, es necesario que sea ampliada mediante la descripción e interpretación de procesos sociales locales, regionales, nacionales y americanos de momentos pre $y$ posthispánicos que evidencien interrelaciones y continuidades, heterogeneidades y conflictos entre los distintos grupos humanos pasados.

En el MTA existe una ruptura espacial y metafísica en la exhibición dada por la supuesta discontinuidad cultural de los grupos originarios luego de la conquista española que conlleva a la separación del objeto y a una demarcación del sujeto, en este caso el indígena. De este modo, se genera una división entre lo histórico y lo arqueológico. La primera 
constituida por el pasado más cercano: colonial, revolucionario, de conformación del estado-nación hasta momentos relativamente recientes; la segunda, representada por el pasado lejano y exótico, el de los pueblos indígenas. Esta situación se evidencia en el MTA por una continuidad temporal a lo largo de miles de años que se ve escindida espacialmente respondiendo justamente a un criterio de organización cronológico siendo los materiales arqueológicos e indígenas presentados casi exclusivamente en la sala de abajo. Mientras que arriba sólo se cuenta con ocho piezas arqueológicas correspondientes al fortín Machado y un acotado tratamiento a los grupos indígenas después de la conquista española. Siguiendo el recorrido propuesto por el museo, la historia posthispánica del partido comenzaría a mediados del siglo XVIII con el recorrido del jesuita J. Cardiel, quedando el período colonial mencionado brevemente en una mínima fracción de la sección. Esta situación también se repite en el MSC, en donde la línea de la exposición cronológica salta de la sala de los grupos indígenas prehispánicos cazadores-recolectores - donde brevemente se explica el poblamiento americano y los modos de subsistencia - a la vida rural de fines del siglo XIX (Figura 3B) sin explicación de ningún proceso económico, social, cultural e histórico pre y posthispánico. Asimismo, tanto la cartelería de las piezas expuestas en esta última sala del MSC como la referida a los objetos correspondientes al sepulcro de Dos Naciones en el ML son de tipo descriptiva, con un lenguaje "neutral", siguiendo un relato de corte histórico-cultural, sin un contexto de referencia y sin problematizar ese pasado.

Esta breve referencia a este período y la falta de materiales arqueológicos sobre sitios posthispánicos en general, se debe a que recién comenzaron a ser abordados sistemáticamente en el año 2006 por la autora en los partidos de Tres Arroyos y San Cayetano (Bagaloni, 2014). En estos partidos, los grupos indígenas cazadores-recolectores sufrieron distintos cambios durante el período colonial que afectaron, entre otros aspectos, su territorialidad, su rango de movilidad, sus estrategias de subsistencia y su organización social. A su vez, la población criolla comenzó a instalarse efectivamente entrada la segunda mitad del siglo XIX, a pesar de que las primeras enfiteusis fueron realizadas en la década de 1830 (Bagaloni, 2014). Por otro lado, puede ser factible que algunos artefactos de producción indígena (p. ej. boleadoras) pertenezcan a momentos coloniales y posteriores también, como podría suceder con ciertos elementos de la CLA y el MSC.

En este nuevo marco de entendimiento del pasado es relevante destacar el uso reiterado de expresiones tomadas directamente de las fuentes escritas y habituales en los trabajos de historiadores y también de arqueólogos, como por ejemplo: "conquista del desierto", "campaña al desierto", "frontera contra el indio", "tierra adentro", "embestidas indígenas", "malones", "indios amigos", "perseguir a la indiada", entre otras, y que algunas se perpetúan en los afiches de los museos estudiados como en el MTA y en el MSC. Estos conceptos, en muchos casos, poseen un sentido valorativo sobre las relaciones interétnicas y los procesos que se sucedieron en el pasado. Por eso, estas nociones aún continúan siendo reflexionadas en el ámbito de la arqueología histórica para proponer otros términos de carácter antropológico que faciliten la interpretación o el análisis de distintos procesos mencionados anteriormente, con el fin de superar la recreación contemporánea de estereotipos del siglo XIX.

Por último, para el caso del MTA, el grupo de investigación conformado por la Dra. M. L. Endere y equipo (Chaparro, 2012; Conforti, 2012; Conforti et al., 2007; Endere, 2004) efectuó distintos estudios sobre este museo antes, durante y posteriormente a los momentos de su conformación. Conforti (2012) desarrolló un análisis sobre la muestra de Arroyo Seco 2, considerando lo que se exhibe y lo que no (p. ej. restos humanos de AS2). Además, se evaluó a corto plazo las percepciones, el entendimiento, el comportamiento, las motivaciones, las ganancias cognitivas y afectivas del público y la valoración del patrimonio arqueológico expuesto en el museo. En este sentido, se refiere al proceso de valoración y de intercambio del cual son parte los visitantes, las 


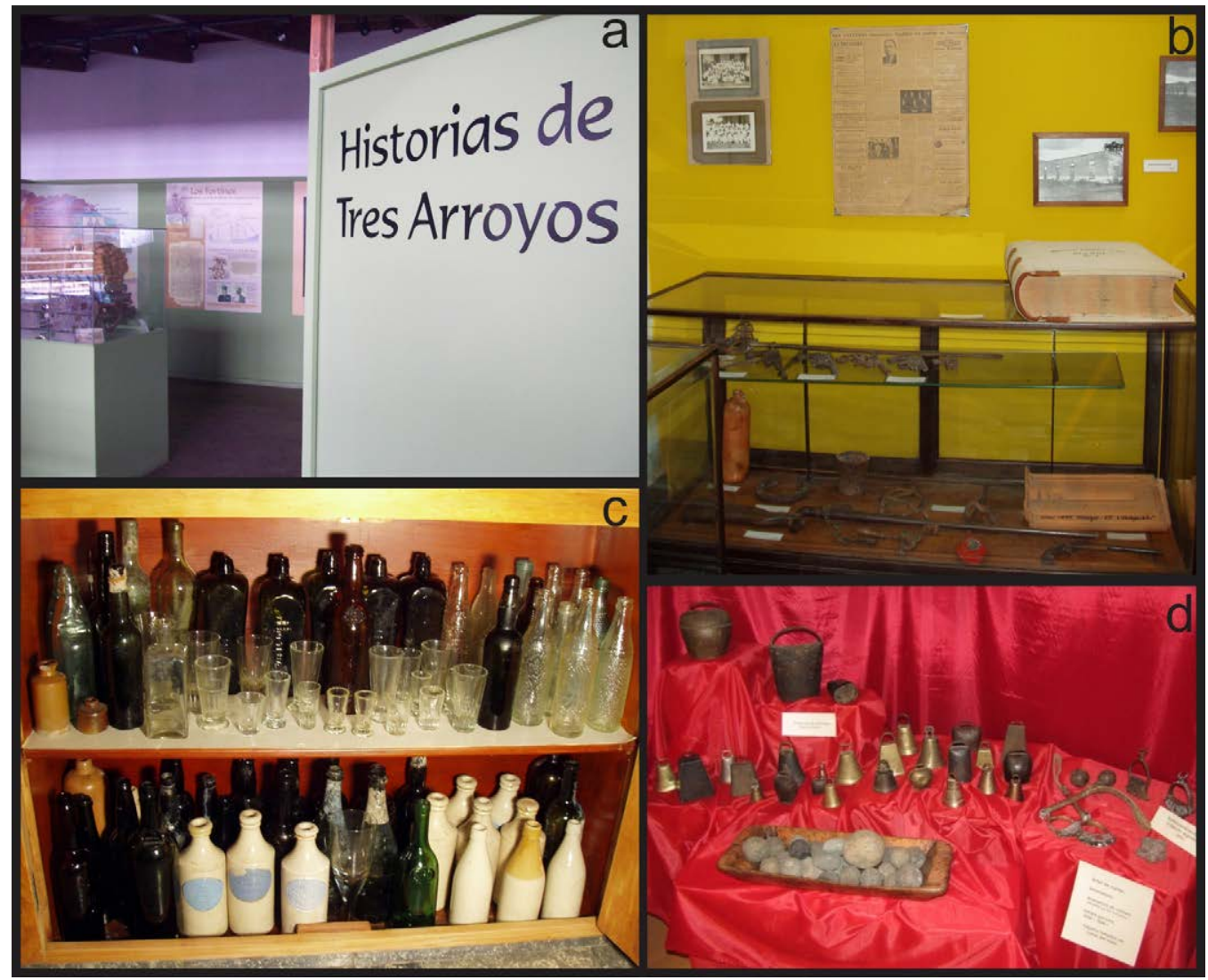

Figura 3. Exposiciones. A) inicio recorrido sala histórica arriba, MTA; B) sala histórica, MSC; C) vitrina Museo del Mate, CM; D) exposición Bicentenario San Cayetano, CLA.

instituciones y grupos de la comunidad. Conforti destaca a través de su investigación la fuerte relación entre ámbitos de educación formal como son las escuelas de niveles iniciales, primarios y secundarios con un ámbito de educación no formal como es el museo, considerándolo como un espacio alternativo para "diseñar nuevas estrategias de aprendizaje, difusión y transferencia del patrimonio arqueológico, en el complejo proceso de construcción social del conocimiento" (Conforti, 2012, p. 136). En cuanto a la identidad de los habitantes de Tres Arroyos un estudio de Endere previo a la formación del nuevo museo, indica que la misma se encuentra fuertemente ligada a la llegada de los colonos agricultores holandeses y daneses - situación que se da en las dos últimas décadas del siglo XIX - negando y/o desconociendo el pasado indígena así como el hispano-criollo anterior (Endere, 2004). Ese pasado indígena que comenzó a hacerse visible con las intervenciones en Arroyo Seco 2, con sus repercusiones a través de distintos mecanismos de difusión en la comunidad general y con el armado de la muestra en el MTA. Sin embargo, existe un hueco entre el pasado indígena prehispánico y la creación del partido en 1884 que ha comenzado a visibilizarse histórica y arqueológicamente en los últimos años en la historia local. Luego de 10 años de funcionamiento del museo, de la realización de muestras transitorias, de tareas de divulgación en distintos medios locales y regionales así como de tareas de extensión universitaria por parte de la autora (Di Prado et al., 2012), esta situación ha comenzado a revertirse lentamente aunque aún falta mucho camino por andar.

\section{Los aficionados y coleccionistas}

A pesar del aporte de los coleccionistas, primordial en el inicio de la disciplina arqueológica, es relevante científicamente el registro arqueológico contextualizado y que 
se recupera en el marco de una investigación sistemática. Por eso es esencial incorporar al aficionado en la generación de nuevos conocimientos y lazos que articulen a los profesionales con la comunidad (Brichetti, 2009). El Sr. Magret, por ejemplo, participó en el registro de los materiales de Chapar así como de las tareas de prospección junto con nuestro equipo. Además, en el "Museo del Mate", Magret armó una vitrina con los materiales vítreos y cerámicos recuperados en Chapar (Figura 3C) sosteniendo un relato del pasado reciente que se complementa con puntas de flecha y boleadoras que fueron halladas en sus campos de San Cayetano. De este modo, a través de la colaboración con profesionales, este coleccionista incorporó un discurso más acabado y consciente del pasado, transmitiendo su importancia a aquellos que concurren a su museo informal que se encuentra abierto tanto a la comunidad sancayetanense como a cualquier visitante de la ciudad.

Un caso distinto es el de la CLA. Cuando entrevistamos a López Alfaro presentó un relato histórico sesgado, de grandes proezas y acontecimientos militares forjando un discurso idílico y parcial, arrastrado por la familia durante varias generaciones. Esta narración recortada del pasado también se transmitió en la muestra desarrollada en el año 2011 en la Municipalidad de San Cayetano, a través de la exposición de objetos de la familia López Alfaro con motivo del "Bicentenario". De esta forma, se sustentó el nacimiento del estado-nación argentino a partir de una serie de hechos históricos incompletos y fragmentados. La conformación y consolidación del estado-nación se configuró, según esta muestra, como consecuencia de la conquista de nuevos espacios territoriales por parte de los sectores oligárquicos criollos, que incluían a grandes estancieros y condecorados militares, en detrimento del papel activo y relevante que tuvieron distintas parcialidades indígenas así como otros grupos étnicos en la negociaciones comerciales y de paz, en la conformación de la independencia y la identidad nacional durante todo el siglo XIX. Esta muestra fue difundida por el portal de noticias Caynet el 17 de Marzo de 2011 a través de la nota "El centenario en el Bicentenario, una muestra histórica" escrita por la Lic. M. Massa (2011). En este contexto, además, se hizo caso omiso del MSC, que tiene una sala de exposiciones transitorias. En el recorrido de la muestra el pasado indígena se ve recortado, con un papel desdibujado en el bicentenario y solamente representados por un par de bolas de boleadoras pertenecientes a dicha familia (Figura 3D).

\section{Discusión y comentarios finales}

Los relatos que acompañan las colecciones públicas y privadas nos han aportado distintos discursos sobre el pasado que vienen siendo transmitidas de múltiples formas. Por un lado, la mirada sesgada de la CLA, unificada, descontextualizada y parcial del/ los pasado/s indígena/s, enalteciendo la figura del militar y del terrateniente en el relato local y regional a partir de proezas salvadoras en algunas batallas criollo-indígena como "Sol de Mayo" y "Cristiano Muerto" (1857) y de los "malones" efectuados por determinadas parcialidades originarias (Rojas Lagarde, 1995). Esta visión de los pueblos originarios posthispánicos que se evidencia en las exposiciones privadas y públicas antes mencionadas (en estas últimas por omisión, invisibilización o incompletitud) es la que también prevalece, por ejemplo, en distintos museos municipales ubicados en ciudades que antiguamente constituyeron la denominada "última frontera bonaerense" al oeste de la provincia de Buenos Aires donde aún se sostiene un discurso hegemónico del origen local y nacional basado en historias de sacrificio de los pobladores inmigrantes, "los pioneros", quienes tenían en el origen de sus problemas a los "salvajes y bárbaros" pueblos indígenas (Nagy, 2013; Podgorny y Lopes, 2008).

Por otro lado, una mirada más plural de las voces y de los actores sociales, como los grupos originarios dentro de las minorías, que primeramente vivieron en esas 
tierras y luego formaron parte del espacio fronterizo y tuvieron un papel activo en la conformación del estado-nación durante el siglo XIX, de los complejos contextos y procesos que se dieron a partir de la conquista española, de los cambios desarrollados por los grupos indígenas a partir de este contacto, de los múltiples espacios comunes de acción y conflicto. No obstante, esta mirada aún no es una mirada democratizadora ni integral ya que en su construcción no se encuentran representados los discursos de los sectores minoritarios sino a través de discursos elaborados por terceros y que los involucran pasivamente, encontrándose aquí un punto de tensión y conflicto.

En este sentido, debemos continuar en la elaboración de una visión completa y conjunta de la etapa colonial y postcolonial para que no se reduzca nuestra historia a la llegada de los europeos ni a la llegada de inmigrantes a fines del siglo XIX y que incorpore todos los tiempos históricos hasta la actualidad así como la totalidad de actores, procesos y contextos que se dieron y surgieron desde el siglo XVI en adelante. Dentro de esta línea se pretende romper con la mirada homogénea de la "identidad nacional" intentando valorar la diversidad cultural, multiculturalidad, la plurietnicidad y las múltiples lenguas, permitiendo así una continuidad entre el pasado prehispánico, el pasado posthispánico y el presente indígena.

Como profesionales tenemos el desafío de evaluar críticamente estos conjuntos de materiales arqueológicos, el compromiso y la responsabilidad de profundizar, ampliar, reforzar, cuestionar, reformular, resignificar y cambiar, según el caso, los discursos presentes y vigentes sobre el pasado reciente junto con el resto de la comunidad local, propiciando la inclusión de las diversas voces pasadas y presentes mediante la construcción de vínculos comunitarios e identitarios, a la par y sin dejar de lado la producción de conocimiento, narrativas y discursos, en los ámbitos no académicos. Haciendo visible, a su vez, las desigualdades históricas, los disensos y los conflictos entre los ámbitos académicos y no académicos y dentro de cada uno de estos. Sin dudas, es necesario un nuevo discurso superador que contemple todas las voces y donde su narración represente las tensiones y miradas de los distintos sectores involucrados histórica y actualmente.

En suma, a lo largo de este artículo se ha valorado positivamente la importancia de las colecciones arqueológicas en distintos momentos de la investigación de la microrregión abordada siendo indudable su aporte dentro de un marco crítico. De igual forma, estimamos los contextos de exposición en los que se hallan insertas estas colecciones actualmente. A pesar de la visión eurocentrista que acompañó a los primeros museos bonaerenses, centrados en un padre fundador y en colecciones privadas (Mazzia, Salerno y Pupio, 2014; Nagy, 2013; Podgorny, 2005; Pupio, 2005), en el caso de los tres museos abordados creados en la segunda mitad del siglo XX se destaca una visión naturalista y/o antropológica desde los momentos iniciales de la creación de los mismos impulsada por las comunidades locales, grupos de aficionados y profesionales. Se evidenció un interés por la prolongación del proceso histórico, los contextos históricos locales y regionales en el MTA y en el MSC aunque con menor profundidad. A pesar de este intento, los períodos colonial y postcolonial se encontraron desdibujados arqueológica e históricamente, invisibilizándose parte del pasado, no sólo el papel activo de las comunidades indígenas locales y regionales durante esos períodos sino también de los primeros pobladores fronterizos provenientes de éste u otros grupos étnicos y sociales como, por ejemplo, el europeo, el negro, el criollo, el mestizo. Es decir, el mundo indígena se limita al período prehispánico o "prehistórico", desconectando $\mathrm{el} / \mathrm{los} \mathrm{pasado} / \mathrm{s}$ indígena/s prehispánico/s de su/s pasado/s posthispánico/s dentro del relato de su/s contextos y procesos en el marco de la etapa colonial, revolucionaria o de construcción del estado-nación argentino y de su historia oficial. De esta manera, implícitamente, se reproducen narrativas y discursos hegemónicos y obsoletos acerca de los pueblos indígenas que habitaron la región pampeano-patagónica a partir del siglo 
XVI. Esta visión ha sido criticada y resignificada desde distintos campos de estudio (antropología, arqueología, etnohistoria, historia) mediante discursos superadores que implican un reconocimiento del papel activo en el pasado y en el presente de los grupos originarios no sólo en Argentina sino en Sudamérica (Borzone y Colli, 2008; Endere y Mariano, 2013; Hernández Llosas, Nancucheo, Castro y Quinteros, 2010; Mazzanti, 2010; Rivolta, Montenegro, Menezes Ferrerira y Nastri, 2014). Paralelamente, un punto a destacar para la zona de estudio es la ausencia de grupos actuales locales que se autoproclamen descendientes de los pueblos originarios. Distinto es el caso regional, donde surgieron en las últimas décadas grupos de descendencia en proceso de autoreconocimiento social en las localidades de Olavarría, Azul, Tandil y Mar del Plata, quienes cuestionan determinados discursos sobre el pasado local y regional (Brichetti, 2010; Pedrotta y Tancredi, 2010; entre otros) ${ }^{2}$.

Por otro lado, el carácter excepcional de los sitios arqueológicos posthispánicos fronterizos y rurales pampeanos les otorga un valor especial y prioritario que debería estar contemplado en las políticas locales y provinciales de gestión del patrimonio cultural. En este sentido, es imprescindible contar prontamente con una legislación que garantice su adecuado resguardo y preservación. La Ley Nacional 25.743/03 de Protección del Patrimonio Arqueológico y Paleontológico a pesar que fija competencias exclusivas y concurrentes a nivel nacional y provincial, que crea un registro nacional de yacimientos, colecciones y objetos arqueológicos y un registro de infracciones entre otros ítems, no contempla orientar al investigador en su accionar, en aspectos de conservación y plan de manejo de estos recursos, el turismo y la regularización de los coleccionistas privados. En la provincia de Buenos Aires, a través de la ley 10.419 de Patrimonio Cultural (1986), solamente se protege aquellos bienes que previamente fueron declarados bien de patrimonio cultural, excluyendo a los sitios no declarados, los hallazgos casuales o los que se produzcan en el contexto de una obra. Desde la experiencia de diez años de trabajo en la región, observamos las variadas colecciones arqueológicas privadas en la mayoría de estancias y casas visitadas, la existencia de sitios arqueológicos históricos (p. ej., basurales históricos, estructuras en pie, montículos) donde los propietarios de estos inmuebles establecieron a lo largo de los años su propio manejo e intervención de los mismos, la mención de la pérdida, destrucción y/o intercambio de piezas, entre otras situaciones. Este tema es para el desarrollo futuro de otro artículo que trata particularmente la gestión pública y privada del patrimonio arqueológico en la microrregión estudiada.

Finalmente, cabe destacar que fue fundamental en el inicio del proyecto de investigación, el estudio de las colecciones públicas y privadas, lo que permitió un primer acercamiento a la comunidad y a las problemáticas abordadas así como fomentar una mayor conciencia de la revalorización del paisaje fronterizo y rural pampeano. Así, este artículo pretendió ser una mirada actual de la importancia de las colecciones arqueológicas en una microrregión y su reguardo para las próximas generaciones. Este estado de la cuestión es el inicio de múltiples líneas futuras de abordaje y de concientización, entre ellas, continuar con proyectos de registro y mapeo de repositorios patrimoniales - sobre todo privados-, fomentar el trabajo interdisciplinario con especialistas en patrimonio, profundizar las actividades donde participen distintos actores sociales de las comunidades locales, generar ámbitos de debate, reflexión y educación; cooperar en la realización de planes de gestión del patrimonio arqueológico a corto, mediano y largo plazo y apoyar el turismo rural.

\section{Agradecimientos}

Agradezco a los directores y personal de los MTA, MSC y ML así como a las familias de O. Magret y de A. López Alfaro de San Cayetano por su buena predisposición. A
2. En el marco del producto audiovisual de divulgación científica "Lucía: una miniserie que desafía los relatos sobre identidad" (Chaparro y Conforti, comunicación personal, 2015) se pretendió mejorar el impacto social de los resultados de las investigaciones científicas desarrolladas en la región centro-sur bonaerense y promover la valoración de los pueblos originarios, para ello se incluyó en el relato la voz de los representantes indígenas Delia Caniumir, Verónica Cestac, Mirta Millán y Víctor Hugo González Catriel, junto con distintos científicos. El relato busca enfatizar la negación de los pueblos originarios como poblaciones milenarias, el reclamo de las tierras, la negación del genocidio y de crímenes de lesa humanidad en los discursos a lo largo de la historia argentina que comienzan a visualizarse cada vez más y por otro lado, se pone en relieve la continuidad de tradiciones ancestrales mediante el relato oral y la memoria activa familiar como ocurre, específicamente, con el caso de la tejedora azuleña Verónica Cestac. 
Betty Queipo y Oscar Oldano por su hospitalidad. A María Eugenia Conforti por la revisión crítica de este manuscrito. A los evaluadores anónimos cuyos comentarios enriquecieron este artículo. El desarrollo de esta investigación se enmarcó en los proyectos dirigidos por la Dra. V. Pedrotta "Arqueología e historia de la frontera sur de Buenos Aires durante la segunda mitad del siglo XIX: campos, ejidos y tierras indígenas desde una mirada interdisciplinar" (PIP CONICET N³04/17) y "La construcción del territorio en la frontera sur de Buenos Aires en perspectiva arqueológica e histórica. Campos, ejidos y tierras indígenas en la segunda mitad del siglo XIX" (PICT AGENCIA $\mathrm{N}^{\circ}$ 219/16). Todo lo expuesto en este artículo es de mi exclusiva responsabilidad. 


\section{Q Referencias citadas}

"Bagaloni, V. N. (2014). Arqueología de los asentamientos fronterizos en el sudeste bonaerense (siglo XIX). (Tesis Doctoral inédita), Universidad Nacional del Centro de la Provincia de Buenos Aires, Argentina.

" Bagaloni, V. N. (2017). Aporte al estudio de materiales vítreos en contextos fronterizos y rurales: la casa de negocio Chapar (partido de Gonzales Chaves, provincia de Buenos Aires). Intersecciones en Antropología, 18,113-118.

» Ballart Hernández, J.y Tresseras, J. J. I (2001). Gestión del Patrimonio Cultural. Barcelona: Ariel.

»Bonomo, M. (2005). Costeando las llanuras. Arqueología del litoral marítimo pampeano. Buenos Aires: Sociedad Argentina de Antropología.

» Borzone, C. A. y Colli, A. (2008). Patrimonio arqueológico y procesos de mercantilización. La relación entre el estado, los pueblos originarios y la comunidad científica. En A. M. Rochietti, Y. Martini e Y. Aguilar (Comps.), Patrimonio cultural: perspectivas y aplicaciones (pp. 93-106). Río Cuarto: Universidad Nacional de Río Cuarto.

"Brichetti, I. E. (2009). Museos regionales en el Sudeste de la Provincia de Buenos Aires. Una aproximación a la problemática del patrimonio arqueológico. Intersecciones en Antropología, 10, 17-25.

"Brichetti, I. E. (2010). Los pueblos originarios y la lucha por la inclusión en el espacio patrimonial local. En R. Bárcena y H. Chiavazza (Eds.), Arqueología Argentina en el Bicentenario de la Revolución de Mayo (Tomo II, pp. 485-489). Mendoza: Universidad Nacional de Cuyo e INCIHUSA-CONICET.

»Casamiquela, R. M. (1969). Diagnosis de restos humanos exhumados de una sepultura indígena bonaerense. Boletín de Divulgación Cultural $\mathrm{N}^{\circ}$. Lobería: Museo de Historia y Ciencias Naturales del Club de Pesca.

"Casamiquela, R. M. y Noseda, G. P. (1970). Diagnosis de restos humanos exhumados de una sepultura indígena bonaerense. Etnia, 11, 16-23.

"Chaparro, M. G. (2012). Los museos como referentes materiales de un pasado comunitario. Primeras aproximaciones al estudio de los museos bonaerenses: el caso del partido de Olavarría. Trabajo presentado en el Seminario Permanente del Centro de Antropología Social IDES. Buenos Aires, Argentina.

" Colasurdo, M. E., Sartori, J. y Escudero, S. (2010). La implicancia de la memoria y la identidad en la constitución del patrimonio. Algunas reflexiones. Revista del Museo de Antropología, 3, 149-154.

"Conforti, M. E. (2012). El público y el patrimonio arqueológico. El caso de la comunidad de Tres Arroyos en relación con el sitio "Arroyo Seco 2" y la muestra del Museo Municipal “José A. Mulazzi”. Revista del Museo de Antropología, 5, 131-140.

»Conforti, M., Endere, M. L. y Martín, D. (2007). El Patrimonio Arqueológico en relación a la educación no formal, la comunicación y la exhibición. El caso del Museo Municipal José A. Mulazzi de la ciudad de Tres Arroyos, Provincia de Buenos Aires. Trabajo presentado en las Quintas Jornadas Técnicas sobre: Conservación, Exhibición y Extensión Educativa en Museos. Río Cuarto, Argentina.

» Crivelli, E., Eugenio, E., Pardiñas, U. y Silveira, M. (1997). Archaeological investigation in the plains of the Province of Buenos Aires, Llanura Interserrana Bonaerense. Quaternary of South America and Antarctic Peninsula, 10 (1994), 167-207. 
»Curtoni, P y Endere, M. (2003). Teoría y práctica arqueológica en Sudamérica. Algunas reflexiones. En R. Curtoni y M. Endere (Eds.), Análisis, Interpretación y Gestión en la Arqueología de Sudamérica (pp. 7-15). Olavarría: Universidad Nacional del Centro de la Provincia de Buenos Aires.

» Di Prado, V., Matarrese, A., Bagaloni, V., Bonomo, M., Prates, L., Angrizani, R. y Madrid, P. (2012). Arqueología, Educación y Museos. Encuentros entre investigadores y comunidades locales. Experiencias en extensión 2012 (FCNyM, UNLP), 1-6.

» Dujovne, M. (1995). Entre musas y musarañas. Una visita al museo. Buenos Aires: Fondo de Cultura Económica.

»Endere, M. L. (2004). Arqueología, Patrimonio y Comunidad local. El caso de Arroyo Seco 2, Partido de Tres Arroyos, Provincia de Buenos Aires. En G. Martínez, M. Gutiérrez, R. Curtoni, M. Berón y G. Madrid (Eds.), Aproximaciones arqueológicas pampeanas. Teoría, métodos y casos de aplicación contemporáneos (pp. 451-468). Olavarría: Universidad Nacional del Centro de la provincia de Buenos Aires.

»Endere, M. L. (2009). Algunas reflexiones acerca del patrimonio. En Endere, M. y Prado, J. (Eds.), Patrimonio, ciencia y comunidad. Su abordaje desde los partidos de Azul, Olavarría y Tandil (pp. 17-46). Olavarría: Universidad Nacional del Centro de la Provincia de Buenos Aires.

» Endere, M. L. y Mariano, M. (2013). Patrimonio en conflicto: entre el interés público y la protección de los derechos indígenas. En J. R. Bárcena y S. E. Martín (Eds.), Libro de resúmenes del XVIII Congreso Nacional de Arqueología Argentina. Arqueología Argentina en el Bicentenario de la Asamblea General Constituyente del Año 1813 (pp. 109-110). La Rioja: Universidad Nacional de La Rioja.

»Endere M. L. y Pedrotta, V. (2010). ¿Para qué hace falta una ley? Venturas y desventuras de un anteproyecto de ley para la provincia de Buenos Aires. En M. Berón, L. Luna, M. Bonomo, C. Montalvo, C. Aranda y M. Carrera Aizpitarte (Eds.), Mamül Mapu: Pasado y Presente desde la Arqueología Pampeana (Tomo I, pp. 445-470). Ayacucho: Libros del Espinillo.

» Endere, M. L., Mariano, M, Conforti, M. E. y Mariano, C. (2015). La protección legal del patrimonio en las provincias de Buenos Aires, La Pampa y Río Negro. Viejos problemas y nuevas perspectivas. Intersecciones en Antropología, 16, 207-219.

»Eugenio E., Aldazábal, V. y Silveira, M. J. (2007). El yacimiento arqueológico La Raquel Sitio 2, Partido de Gral. Lamadrid, Buenos Aires. En F. Oliva, N. De Grandis y J. Rodríguez (Comp.), Arqueología Argentina en los Inicios de un Nuevo Siglo (Tomo I, pp. 239-250). Rosario: Laborde Editor.

» Funari, P. (2004). Arqueología Latinoamericana y su contexto histórico: la arqueología pública y las tareas del quehacer arqueológico. En A. Haber (Comp.), Hacia una arqueología de las arqueologías sudamericanas (pp. 83-90). Bogotá: Ediciones Uniandes y Centro de Estudios Socioculturales e Internacionales (CESO).

» Gómez Romero, F. (2007). Sistemas de relaciones sociales en la frontera sur de Buenos Aires: Yacimientos fortín Miñana (1860-1863) y fortín Otamendi (1858-1869). (Tesis Doctoral inédita), Universidad Autónoma de Barcelona, España.

» Guinnard, A. ([ca.186o] 1941). Tres años de esclavitud entre los Patagones. Buenos Aires: Colección Austral.

» Guráieb, A. G. y Frère, M. M. (2008). Caminos y encrucijadas en la gestión del patrimonio arqueológico argentino. Ciudad Autónoma de Buenos Aires: Facultad de Filosofía y Letras. 
» Hernández Llosas, M. I., Ñancucheo, J., Castro, M. y Quinteros, R. (2010). Conocimientos compartidos para la re-significación del patrimonio arqueológico en Argentina. En I. C. Jofré (Coord.), El regreso de los muertos y las promesas del oro. Patrimonio arqueológico en conflicto (pp. 31-68). Córdoba: Encuentro Grupo Editor.

»Incendio en el Museo Faustino Queipo (2013, mayo). Caynet. Recuperado de http://www. caynet.com.ar/news.php?id=11109.

» Mariano, C. y Conforti, M. E. (2013). Del registro al patrimonio, un camino con curvas cerradas. Gestión del patrimonio arqueológico y comunicación pública de la ciencia. Revista Colombiana de Antropología, 49(1), 279-300.

» Massa, M. (2011, 17 de Marzo). El Centenario en el Bicentenario, una muestra histórica. Caynet. Recuperado de http://www.caynet.com.ar/news.php?id=8683.

» Massigoge, A. (2009). Arqueología de los cazadores-recolectores del sudeste de la región pampeana: una perspectiva tafonómica. (Tesis Doctoral inédita), Universidad Nacional de La Plata, Argentina.

» Mazzanti, D. (2010). Factores dominantes en el desarrollo de la arqueología pampeana del período postconquista. En J. Nastri y L. Menezes Ferreira (Eds.), Historias de Arqueología Sudamericana (pp. 189-209). Buenos Aires: Fundación de Historia Natural Félix de Azara.

» Mazzia, N., Salerno, V. y Pupio, A. (2014). Public Archaeology as a reflexive Practice: An Argentine Case Study in the Pampean region. En S. Thomas y J. Lea (Eds.), Public Participation in archaeology (pp. 61-70). Woodbridge: The Boydell Press.

»Nagy, M. A. (2013). Los museos de la última frontera bonaerense y sus narrativas acerca de los pueblos indígenas. Revista del Museo de Antropología, 6, 79-9o.

»Pedrotta, V. (2005). Las sociedades indígenas del centro de la provincia de Buenos Aires entre los siglos XVI y XIX. (Tesis Doctoral Inédita), Universidad Nacional de La Plata, Argentina.

»Pedrotta, V. y Tancredi, M. (2010). Simbolismo, apropiaciones y conflictos en torno a los reclamos de restitución del cráneo de Cipriano Catriel. En I. C. Jofré (Coord.), El regreso de los muertos y las promesas del oro. Patrimonio arqueológico en conflicto (pp. 141-168). Córdoba: Encuentro Grupo Editor.

» Podgorny, I. (2005). La mirada que pasa: museos, educación pública y visualización de la evidencia científica. História, Ciências, Saúde-Manguinhos, 12 (suplemento), 231-264.

» Podgorny, I. y Lopes, M. (2008). El desierto en una vitrina: Museos e historia natural en la Argentina, 1810-1890. Ciudad de México: Limusa.

»Pupio, M. A. (2005). Coleccionistas de objetos históricos, arqueológicos y de ciencias naturales en museos municipales de la provincia de Buenos Aires en la década de 1950. História, Ciências, Saúde-Manguinhos, 12 (suplemento), 205-29.

»Querol, M. A. (2010). Manual de Gestión del Patrimonio Cultural. Madrid: Ediciones Akal.

» Rivolta, M. C., Montenegro, M., Menezes Ferreira, L. y Nastri, J.(Eds). (2014). Multivocalidad y activaciones patrimoniales en Arqueología: Perspectivas desde Sudamérica. Ciudad Autónoma de Buenos Aires: Fundación de Historia Natural Félix de Azara.

» Rojas Lagarde, J. L. (1995). El malón a Tres Arroyos en 1870 - Malones y comercio de ganado con Chile en el siglo XIX. Buenos Aires: Editorial Faro.

»Salerno, V. M. (2014). Trabajo arqueológico y representaciones del pasado en la provincia de Buenos Aires (Primera edición). Ciudad Autónoma de Buenos Aires: Facultad de Filosofía y Letras. 